\title{
Does Team Make Better Earnings Forecast? : Evidence from China
}

\author{
Lisha $\mathrm{Ma}^{1, \mathrm{a}^{*}}$, Xianwei $\mathrm{Lu}^{2, \mathrm{~b}}$ \\ ${ }^{1}$ Chengdu University of Technology; Southwest Jiao Tong University, China; \\ ${ }^{2}$ Southwest Petroleum University, China \\ *malisha@cdut.cn
}

Keywords: team-individual; behavioral decision theory; analysts forecast; herding behavior

\begin{abstract}
A total of 54,443 analysts earnings forecasts were taken as the study samples on the Chinese securities market in the period of 2007 2010, and the differences in influences from the earnings forecast released in the form of individual and the form of team on the analysts earnings forecast behavior were empirically tested. The study found: Compared with the forecast released in the form of individuals, the forecast released in the form of team had significant differences in the forecast decision-making process, i.e. the forecast released in the form of team had more obvious herding behavior; the forecast released in the form of team featured higher accuracy but poorer timeliness; when the team existed any star analyst, the forecast behaviors would also show significant difference.
\end{abstract}

\section{Introduction}

With the increasing external competition, the team has increasingly become an important operating form of organization economic activities [1]. In the highly competitive securities market, the team behavior is also playing an increasingly important role. As an information intermediary of the securities market, the analyst plays an important role in improving the operational efficiency of the securities market. The growing competitiveness of the job environment has caused the teamwork behavior among analysts increasingly common, which has become the protagonist of the analyst industry. This trend is also reflected in the appraisal of the best analysts by the New Fortune through comparison. According to the data statistics on the New Fortune magazine's website, the best analysts in various industries were all individuals in 2003, but by the end of 2013, the first of the best analysts were all research teams (research groups), and among the top five award winners, the individual best analysts accounted for about $10 \%$. The collectivism is the main cultural characteristics of Chinese society, and under the cultural background dominated by collectivism, the team behavior is more common in the Chinese economic activity, and the forecast behaviors of the analysts show significant differences under different cultural backgrounds [2]. Therefore, whether the earnings forecasts released by team are significantly different from those released by individual analysts? This paper will discuss on the above issues.

\section{Research Hypotheses}

In the modern economic society, the decision-making method in form of team exists throughout the modern economic society. The release of forecast by analyst in the form of team is gradually playing an important role. From the perspective of the benefit maximization, the classical decision theory argues that there is no difference between the individual and team decision-making; and the behavioral decision theory argues that individuals are more prone to cognitive biases in decision-making, and the team decision-making behavior is less influenced by the behavior and therefore more close to rational decision-making [3]. The studies by Kocher and Sutter found that 
the team did not exhibit more rational decision-making than individuals, but had stronger ability to learn [4].

On the other hand, the differences between individual decision-making and team decision-making under the behavioral decision theory have also been proven. The studies of Blinder and Morgan also supported the conclusions that the team decision-making was superior to individual decision-making, and that the team decision-making had better timeliness [5]. Casari et al. made experimental findings using the company's merger \& acquisition (M\&A) test, and determined that the team $M \& A$ decisions were superior to individual $M \& A$ decisions [6]. Therefore, proceeding from the behavioral decision theory, the earnings forecasts released in form of team are significantly different from those released in the form of individual in term of the decision-making efficiency. Therefore, we propose the following hypothesis:

H1: Compared with the earnings forecast in the form of individuals, the earnings forecast released in form of team is more accurate.

Compared with individuals, when faced with the same task, the team can reduce the completion time by decomposition of tasks [7]. Based on the results of the experiment, when faced with the same task, the group's ability to learn and timeliness of decisions are superior to individuals [5]. The earnings forecast specific to the target company is based on collection, collation and analysis of extensive information. The team can ease the restrictions on individual time and energy through the decomposition of task, so that the timeliness of the forecast release is improved. The studies of Brown and Hugon also showed that the team forecast was better than individual forecast in term of timeliness [7]. Therefore, we propose the following hypothesis:

$\mathrm{H}$ 2: Compared with earnings forecast made in the form of individuals, the earnings forecast released in the form of team is better in timeliness.

The analysts tend to release forecast closer to market expectations when making earnings forecast, and such herding behavior during the forecast decision-making process by analysts has been proved by many scholars. Since the efficiency of decision making by analyst is influenced by the policy-makers structure (group and individual), the decision-making process as the decision efficiency front-end of the analysts is also influenced by the decision-makers structure. The studies of Masclet et al. concluded by using lottery-choice experiment that in an uncertain decision-making environment, the team decision-making was more conservative [8]. Then such conservative decision-making behavior was more prone to using external expectation as reference point and thus generated herding behavior. He and Villeval made experimental study on how to aggregate individual preferences into the group, and the findings showed that team members with intermediate preferences drove the team decisions [9]. Therefore, we propose the following hypothesis:

H3: Compared with earnings forecast in the form of individuals, the herding effect of the earnings forecast released in the form of team is more apparent.

\section{Research Design}

Team forecast (TEAM). With reference to the study of Brown and Hugon [7], this paper measures whether belonging to the earnings forecast through the signatures for the earnings forecast released by the analyst. If the number of persons who sign the released earnings forecast is at least two, the earnings forecast is team forecast i.e. TEAM and the assigned value is 1 , and otherwise the assigned value is 0.Analysts forecast accuracy (Accuracy). In this paper, the actual value of the predicted value minus the actual year EPS divided by the value of the difference between the actual value of the absolute value as a measure of forecast errors.Analysts predict timeliness $(L F R)$. With reference to the study results of Cooper et al. [10], this paper uses the leading degree to measure analysts' forecast release timeliness. Herding behavior of the analyst forecast (HERDing). With reference to the studies of the Hong et al. [11], the herding behavior of the analysts forecast in this paper is measured as Hong et al. [11].

This paper also describes the control of other factors that affect the forecast behavior of analyst: 
For the star analyst of the year (NSTAR), if the individual (team) analyst is on the list of star analysts of the year, the NSTAR value is 1, or otherwise the NSTAR value is 0; For the star analyst outside the year $(O S T A R)$, if the star analyst was once on the list of star analysts of the previous year, the OSTAR value is 1 , or otherwise the OSTAR value is 0 . If the securities trader that the analyst belongs to is the lead underwriter for releasing the earnings forecast on the target company, the MUNDER value is taken as 1 , or otherwise the MUNDER value is taken as 0 ; if the securities trader that the analyst belongs to is the secondary underwriter for releasing the earnings forecast on the target company, the $S U N D E R$ value is taken as 1, or otherwise the $S U N D E R$ value is taken as 0. $N F B$ is the total number of the earnings forecast report issued on the same year by the securities company where the analyst belongs. In this paper, the number of analysts tracking the target company in 365 days is used to measure the competitive environment (COMP). The company size (SIZE) shall be measured with the log value of the total assets at the year-end of the year; (2) Profitability is measured by the year-end net profit for the year divided by the total assets; (3) Asset-liability ratio $(L E V)$ is measured by the total liabilities at year-end of the year divided by total assets. In addition, this paper also describes the control on the yearly variable (YEAR) and industry variables $(I N D)$.

\section{Empirical Analysis}

Sample Selection and Data Sources. This paper selected the earnings forecasts released by analysts in 2007-2010 and with the $A$-share listed companies in China as the target company as the study sample. In this paper, the study data were sourced from the Shenzhen GTA database (CSMAR). Firstly, the analysts forecast relevant data within the sample interval were obtained from the analysts forecast subdatabase; secondly, the corresponding data on the underwriting relationship with the analyst affiliated securities institutions were obtained from the initial public offering (IPO) subdatabase. Finally, the A-share listed companies' financial characteristics relevant data were obtained from the financial statements subdatabase. On the basis of excluding the samples of data missing, Python software programming was used to match the analysts feature data, underwriters relational data and corporate financial characteristics data on one-to-one basis, and finally a total of 54,443 samples were obtained.

Descriptive Statistics and Correlation Test. As can be seen from Table 1, the average weight of analysts team forecast is up to $30 \%$ in China's securities market, indicating that the analysts team forecast has become an important form of analysts forecast release in China's securities market. According to the study of the Brown and Hugon [7], the analysts team sample on the US securities market accounted for about $6 \%$ of the total sample, while the analysts team forecast released in China accounted for about $30 \%$, which is about 5 times the proportion of forecast released by team in the US securities market, also indicating that the team behavior in China, especially the analyst team behavior is rather popular in China, a country with collectivism as the main cultural characteristics).

Table 1 descriptive statistics

\begin{tabular}{l|r|r|r|r|r}
\hline \multicolumn{1}{c|}{ Variable } & \multicolumn{1}{|l|}{ Mean } & \multicolumn{1}{l|}{ Std.error } & Min & \multicolumn{1}{l}{ Max } & Observation \\
\hline LFR & 3.622 & 8.049 & 0.004 & 313.286 & 54443 \\
\hline TEAM & 0.312 & 0.463 & 0.000 & 1.000 & 54443 \\
\hline NStar & 0.169 & 0.375 & 0.000 & 1.000 & 54443 \\
\hline OStar & 0.187 & 0.390 & 0.000 & 1.000 & 54443 \\
\hline MUNDER & 0.036 & 0.187 & 0.000 & 1.000 & 54443 \\
\hline
\end{tabular}




\begin{tabular}{l|r|r|r|r|r}
\hline SUNDER & 0.010 & 0.101 & 0.000 & 1.000 & 54443 \\
\hline NFB & 632.333 & 440.026 & 1.000 & 1863.000 & 54443 \\
\hline COMP & 23.028 & 14.407 & 0.000 & 83.000 & 54443 \\
\hline ROA & 0.069 & 0.058 & -0.728 & 0.400 & 54443 \\
\hline Size & 23.087 & 1.991 & 19.060 & 30.234 & 54443 \\
\hline LEV & 0.511 & 0.218 & 0.000 & 1.794 & 54443 \\
\hline Accuracy & 0.257 & 0.385 & 0.000 & 8.930 & 54443 \\
\hline HERDing & 0.161 & 0.282 & 0.000 & 8.171 & 54443 \\
\hline
\end{tabular}

Table 2 Regression result

\begin{tabular}{|c|c|c|c|c|c|c|c|c|c|}
\hline \multirow{4}{*}{ TEAM } & \multicolumn{3}{|c|}{$L F R$} & \multicolumn{3}{|c|}{$A C C U R A C Y$} & \multicolumn{3}{|c|}{ HERDing } \\
\hline & (1) & (2) & (3) & (4) & (5) & (6) & (7) & $(8)$ & (9) \\
\hline & -0.070 & 0.162 & 0.119 & -0.041 & -0.071 & -0.083 & -0.005 & -0.008 & -0.007 \\
\hline & $(0.91)$ & $(1.89)^{\mathrm{c}}$ & $(1.36)$ & $(1.23)$ & $(1.93)^{\mathrm{c}}$ & $(2.22)^{b}$ & $(2.13)^{b}$ & $(2.70)^{\mathrm{a}}$ & $(2.35)^{\mathrm{b}}$ \\
\hline \multirow[t]{2}{*}{ Nstar } & 0.147 & 0.639 & 0.155 & 0.109 & 0.045 & 0.107 & 0.004 & -0.000 & 0.004 \\
\hline & $(1.22)$ & $(4.41)^{\mathrm{a}}$ & $(1.29)$ & $(2.12)^{\mathrm{b}}$ & $(0.73)$ & $(2.08) \mathrm{b}$ & $(1.08)$ & $(0.08)$ & $(1.06)$ \\
\hline \multirow[t]{2}{*}{ Ostar } & -0.227 & -0.194 & 0.153 & -0.037 & -0.041 & -0.122 & -0.006 & -0.006 & -0.009 \\
\hline & $(1.91)^{\mathrm{c}}$ & $(1.63)$ & $(1.05)$ & $(0.72)$ & $(0.81)$ & $(1.97) \mathrm{b}$ & $(1.50)$ & $(1.58)$ & $(1.80)^{\mathrm{c}}$ \\
\hline \multirow[t]{2}{*}{ TEAMxNStar } & & -1.154 & & & 0.150 & & & 0.011 & \\
\hline & & $(6.13)^{\mathrm{a}}$ & & & $(1.86)^{\mathrm{c}}$ & & & $(1.77) \mathrm{c}$ & \\
\hline \multirow[t]{2}{*}{ TEAMxOStar } & & & -0.829 & & & 0.186 & & & 0.006 \\
\hline & & & $(4.56)^{\mathrm{a}}$ & & & $(2.39)^{\mathrm{b}}$ & & & $(1.00)$ \\
\hline \multirow{2}{*}{\multicolumn{10}{|c|}{$\begin{array}{l}\text { Other control } \\
\text { variable }\end{array}$}} \\
\hline & & & & & & & & & \\
\hline \multirow[t]{2}{*}{ Constant } & 1.119 & 1.027 & 1.070 & 1.364 & 1.376 & 1.375 & -0.456 & -0.455 & -0.456 \\
\hline & (1.64) & $(1.51)$ & (1.57) & $(4.67)^{\mathrm{a}}$ & $(4.71)^{\mathrm{a}}$ & $(4.71)^{\mathrm{a}}$ & $(20.27)^{\mathrm{a}}$ & $(20.23)^{\mathrm{a}}$ & $(20.25)^{\mathrm{a}}$ \\
\hline F test & 6.6 & 8.2 & 7.3 & 129.4 & 136.4 & 129.5 & 379.1 & 359.3 & 359.2 \\
\hline $\operatorname{Adj}-R^{2}$ & 0.00 & 0.00 & 0.00 & 0.04 & 0.04 & 0.04 & 0.11 & 0.11 & 0.11 \\
\hline Observation & & & & & 54443 & & & & \\
\hline
\end{tabular}

a,b,c represent the statistical significance at the $0.01,0.05$, and 0.1 levels respectively. 


\section{Regression Results Analysis}

Table 2 gives the regression results on whether belonging to team forecast and analysts forecast behavior. From column (1) in Table 2, the TEAM regression coefficient is negative, indicating that compared with earnings forecast released by individual analyst, the earnings forecast released in form of team has lower degree of leading, in other words, the earnings forecast team released by analyst has poorer timeliness, but the regression coefficients did not pass the significance test. From column (4) in Table 4, the TEAM regression coefficient is negative, indicating that compared with earnings forecast released by individual analyst, the earnings forecast released in form of team has higher level of accuracy, indicating that the teamwork and the information advantage of team can help improve the accuracy of forecast, but this regression coefficient did not pass the significance test. From column (7) in Table 2, the TEAM regression coefficient is negative, indicating that compared with earnings forecast released by individual analyst, the earnings forecast released in form of team are more consistent with market expectations, the earnings forecasts in form of team are more inclined to releasing the earnings forecast following the market expectation, so that the herding effect is more apparent.

The star analysts and non-star analysts were significantly different in earnings forecast behavior [12]. From column (2) in Table 2, TEAM*NSTAR regression coefficient is significantly negative, indicating that when the analyst team exists any star analyst of the current year, the earnings forecast released by the team has poorer timeliness; and from column (3) in Table 2, the $T E A M^{*} O S t a r$ regression coefficient is significantly negative, indicating that when the analysts team exists any star analyst of the previous years, the earnings forecast released by the team has poorer timeliness. From column (5) in Table 4, the TEAM *Nstar regression coefficient is significantly positive, indicating that when the analyst team exists any star analyst of the current year, the earnings forecast released by the team has lower accuracy; from column (6) in Table 4, the $T E A M^{*} O S t a r$ regression coefficient is significantly positive, indicating that when the analysts team exists any star analyst of the previous years, the earnings forecast released by the team has lower accuracy. The conclusion and the columns (5) and (6) conclusions showed that in terms of earnings forecast accuracy, the predictive ability of the team having star analyst is significantly weaker than the team without star analyst involved in release of earnings forecast. From column (8) in Table 4, the TEAM*Nstar regression coefficient is significantly positive, indicating that when the analyst team exists any star analyst of the current year, the earnings forecast released by the team deviates greater from the market expectation, the boldness of the earning forecast is higher, the willingness to follow in release is lower; also from column (9) of Table 4, the TEAM*Ostar regression coefficients are positive, indicating that when the analysts team exists any star analyst of the previous years, the earnings forecast released by the team has higher degree of deviation from the market expectations, but this regression coefficient did not pass the significance test.

\section{Conclusions}

With the analyst's earnings forecasts in 2007 2010 in China's securities market as the study sample, empirical test is done to test if the earnings forecast issued in the form of individual analyst have differences from those released in the form of team in term of the forecast process and the forecast efficiency. The study found that compared with the forecasts released in the form of individual, the forecasts released in the form of team exist significant differences in term of the forecast decision-making process, in other words the herding behavior in the forecasts released in the form of team is more obvious; compared with the forecasts released in the form of individual, the forecasts released in the form of team feature higher accuracy and better timeliness, but the regression coefficients did not pass the significance test; Further study showed that if a star analyst existed in the team, the forecast efficiency would be higher. 


\section{References}

[1] S.Choen , D. E.Bailey, What makes teams work: Group effectiveness research from the shop floor to the executive suite, J. manag. 23(1997)239-290.

[2] C.Qi,H.P.Tan, Z.Ran, Incentives or irrationality? international evidence from the impact of individualism on Analyst Forecast Bias,2014. Available at SSRN: http://ssrn.com/abstract $=2385759$

[3] G.Charness, M.Sutter, Groups make better self-interested decisions, J. Econ.Pers, 26(2012)157-176.

[4] M.G.Kocher, M.Sutter, The decision maker matters: individual versus group behavior in experimental beauty-contest games, Econ. J. 115(2005) 200-223.

[5] A. S. Blinder,J. Morgan, Are two heads better than one? monetary policy by committee, J. Mon. Credit. Ban. 37(2005) 789-811.

[6] M.Casari, J.Zhang, C.Jackson, When do groups perform better than individuals? a company takeover experiment. 2011.Available at SSRN: http://ssrn.com/abstract=1873267

[7] L. D. Brown, A.Hugon, Team earnings forecasting, Rev. Accou.Stu. 14(2009)587-607.

[8] D.Masclet, N.Colombier, L. Den-Boe, Group and individual risk preferences: A lottery-choice experiment with self-employed and salaried workers, J.Econ.Behav.Organ. 70(2009) 470-484.

[9] H.He,M.C.Villeval,Are teams less inequality averse than individuals? , 2014.Available at SSRN: http://ssrn.com/abstract=2441936

[10]R. A.Cooper, T. E.Day, C. M.Lewis,Following the leader: a study of individual analysts' earnings forecasts, J. Fina. Econo. 61(2001)383-416.

[11]H.Hong, J. D.Kubik, A. Solomon, Security analysts' career concerns and herding of earnings forecasts ,RAND .J. of Econ.31(2000) 121-144.

[12] G.Hilary, C.Hsu, Analyst forecast consistency , J. Fin, 68(2013): 271-297. 